\title{
Beneficial effects of co-treatment with dextromethorphan on prenatally methadone- exposed offspring
}

\author{
Yao-Chang Chiang ${ }^{1,2}$, Li-Ci Ye ${ }^{3}$, Kuei-Ying Hsu ${ }^{4}$ Chien-Wei Liao ${ }^{4}$, Tsai-Wei Hung ${ }^{4}$, Wan-Jou Lo ${ }^{4}$, Ing-Kang Ho ${ }^{1,2}$ \\ and Pao-Luh Tao ${ }^{3,4^{*}}$
}

\begin{abstract}
Background: Heroin use among young women of reproductive age has drawn much attention around the world. Although methadone is widely used in maintenance therapy for heroin/morphine addiction, the long-term effects of prenatal exposure to methadone and preventative therapy remain unclear. For revealing this question, female pregnant Sprague-Dawley rats were sub-grouped to receive (1) vehicle, (2) methadone $5 \mathrm{mg} / \mathrm{kg}$ at embryonic day 3 (E3) and then $7 \mathrm{mg} / \mathrm{kg}$ from E4 to E20, (3) dextromethorphan (DM) $3 \mathrm{mg} / \mathrm{kg}$, and (4) methadone + DM (the rats received methadone followed by DM treatment), subcutaneously, twice a day from E3 to E20. The body weight, natural withdrawal, pain sensitivity, ED50, conditioned place preference and water maze were conducted at different postnatal stages (P1 to P79) of offspring. The quantitative real-time RT-PCR and electrophysiology were also used to measure the gene expression of opioid receptors in the spinal cord and changes of LTP/LTD in the hippocampus, separately.
\end{abstract}

Results: Prenatal exposure to methadone or DM did not affect survival rate, body weight, water maze and LTP or LTD of offspring. However, prenatal methadone significantly increased the withdrawal symptoms, pain sensitivity, addiction liability and decreased the mRNA expression of pain related opioid receptors. Co-administration of DM with methadone in the maternal rats effectively prevented these abnormalities of offspring induced by methadone.

Conclusions: Our study clearly showed that co-administration of dextromethorphan with methadone in the maternal rats prevented the adverse effects induced by prenatal methadone exposure. It implies that dextromethorphan may have a potential to be used in combination with methadone for maintenance treatment in pregnant heroin-addicted women to prevent the adverse effects induced by methadone on offspring.

Keywords: Prenatal, Opioid, Methadone, Dextromethorphan, Addiction

\section{Background}

Abuse of opioids causes serious social and health problems around the world. Methadone is a synthetic mu- $(\mu-)$ opioid receptor agonist that has been used for maintenance therapy in heroin addicts (including pregnant women) for more than 40 years [1]. Although

\footnotetext{
* Correspondence: pltao@nhri.org.tw

${ }^{3}$ Department of Pharmacology, National Defense Medical Center, Taipei, Taiwan

${ }^{4}$ Center for Neuropsychiatric Research, National Health Research Institutes,

Zhunan, Miaoli County, Taiwan

Full list of author information is available at the end of the article
}

methadone has been shown to be effective in reducing withdrawal symptoms and impulsive injection of opioids [2], chronic use of methadone has also exhibited addictive liability and respiratory depression in some subjects [3]. Recently, an U.S. report showed that $4.4 \%$ of pregnant women used illicit drugs in 2009-2010 [4]. This finding has drawn much attention to this population; and the effects of intrauterine drug exposure on offspring are noticed to be urgent

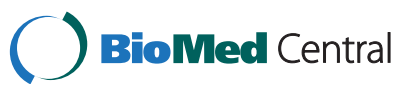

(c) 2015 Chiang et al.; licensee BioMed Central. This is an Open Access article distributed under the terms of the Creative Commons Attribution License (http://creativecommons.org/licenses/by/4.0), which permits unrestricted use, distribution, and reproduction in any medium, provided the original work is properly credited. The Creative Commons Public Domain Dedication waiver (http://creativecommons.org/publicdomain/zero/1.0/) applies to the data made available in this article, unless otherwise stated. 
and important issues. Children born from mothers addicted to opioids (such as heroin and morphine) have been known to suffer from higher mortality and problems with the central nervous system including dysfunction of intellectual ability or emotional control [5,6]. In addition, chronic morphine exposure during adolescence of female rats caused transgenerational effects on anxiety-like behavior and morphineinduced sensitization in the offspring [7]. Our previous studies suggest that offspring, if exposed to opioid prenatally, may experience long-term effects on behaviors and biochemical homeostasis [8]. This indicates that understanding the effects of prenatal opioid exposure on offspring and finding prevention and treatment strategies are important. Methadone is not only a synthetic $\mu$-opioid receptor agonist but also an antagonist for $N$-methyl-D-aspartate (NMDA) receptor, with the majority of the $\mu$-opioid receptor agonist activity residing in the $\mathrm{R}$-isomer [9]. Methadone is also commonly utilized in detoxification and maintenance programs for heroin-addicted patients, including pregnant women $[1,10]$. Some clinical studies of methadone exposure in the pregnancy stage have found that the increase in the incidence of mortality, decrease of birth weight ranges, low head circumference, and mood, attention and cognitive deficits in the methadone-exposed infants as compared to drug-free control [11-13]. Additionally, the neonatal abstinence syndrome (NAS) is characterized to high-pitched crying, hyperactive reflexes, tremors, hypertonicity, convulsions, regurgitation, dehydration, diarrhea etc. [13]. These symptoms are like to the withdrawal syndromes in the rodents. The incidence of NAS in the newborn from MMT mother is typically $60-90 \%$; a large of them presented severe withdrawal and need the pharmacotheraputic intervention [13]. Furthermore, the NAS increases the risk of mortality if it is left untreated [14]. The doses of methadone used for treatment of heroin addicts are wide ranges (50-100 mg/daily) [15], some cases are even closed to $200 \mathrm{mg} /$ daily in previous reports and observation in our cohort $[16,17]$. Several studies suggested that the score of NAS, percentage of treatment for withdrawal, and duration of neonatal hospitalization were positively associated with maternal methadone dosage [18-20]. This may indicate that higher maternal methadone doses cause severe NAS. However, the issue of maternal methadone dose versus the prognosis of NAS remain unresolved, that may due to the inability to appropriately control for numerous confusing factors, such as the health status, personal neglect, poor antenatal care [13]. No matter what these findings provided, a concept that an investigation of possible strategies for reducing the dosage of methadone of maternal use or using a combination of some medicine may be helpful in decreasing adverse effects (mortality, weight gain, or NAS etc.) on offspring that were prenatally exposed to methadone.

Dextromethorphan (DM), a commonly used antitussive agent, is without opioid-like activity [21]. Both DM and its major metabolite dextrophan are NMDA receptor antagonists. DM has also been reported to treat neurologic diseases, such as non-ketotic hyperglycinemia and intractable seizure in neonates $[22,23]$. Results from the epidemiologic analysis of prenatal exposure of therapeutic dose of dextromethorphan (117.2 mg, the maximum dose is $120 \mathrm{mg} /$ daily with $30 \mathrm{mg}$ for 4 times [15]) showed no evidence of teratogenicity in infants [24]. Studies have shown that DM reduced morphine reward as measured by CPP test, and this might be related to DM's antagonizing effect on NMDA receptors that are involved in the activation of mesocorticolimbic dopaminergic systems $[25,26]$. Our previous studies also demonstrated that co-administration of DM with morphine during pregnancy and throughout lactation reduced several morphine-induced adverse effects [27,28] and could prevent higher vulnerability to inflammatory thermal hyperalgesia in rat offspring [29].

Although methadone is also a $\mu$-opioid agonist like morphine, the effects of DM in prenatally methadoneexposed offspring have not been explored. Therefore, in the present study, we aimed to investigate if the prenatal co-administration of DM with methadone prevents or decreases the possible adverse effects induced by methadone on the offspring, such as withdrawal symptoms, changes of pain sensitivity, tolerance, addiction liability (reward), memory impairment, etc.

\section{Methods}

\section{Animals}

Pregnant Sprague-Dawley rats (BioLASCO Taiwan Co., Taipei, Taiwan) and their offspring were used in this study. All animals were housed in an animal room with a 12-h light/dark cycle (light on 07:0019:00), a temperature of $25^{\circ} \mathrm{C}$, and humidity of $50 \pm$ $10 \%$. Pregnant rats were kept individually in separate cages, and their male offspring were housed $2-3$ per cage after weaning. A diet (Prolab 2500 Rodent 5P14, LabDiet, PMI Nutrition International, St. Louis, MO, USA) and water were provided ad libitum. The care of animals was carried out in accordance with institutional and international standards (Principles of Laboratory Animal Care, $\mathrm{NIH}$ ); the animal protocol was approved by the IACUC of the National Health Research Institutes (NHRI-IACUC-099087-A). All experiments were performed following the schedule below. 


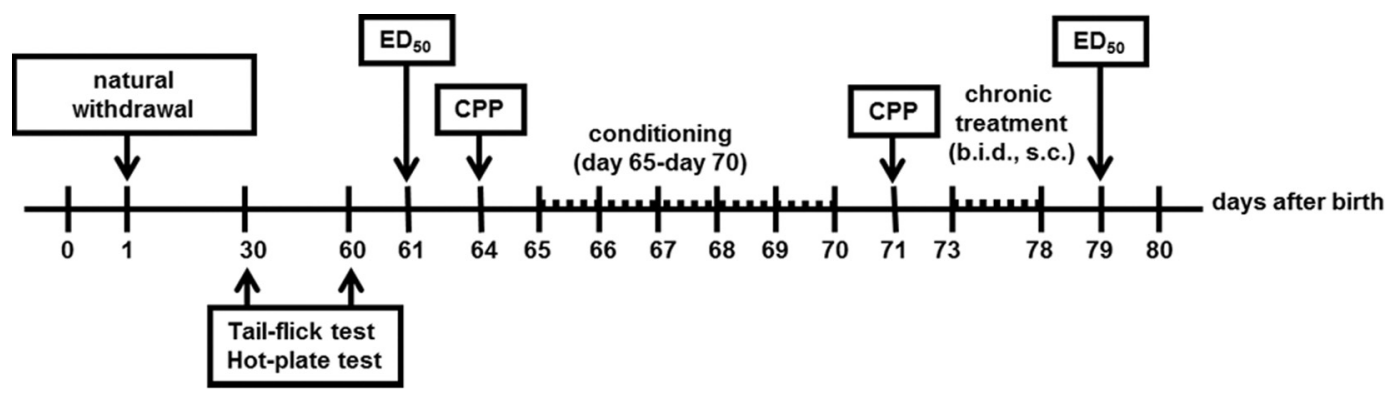

\section{Drugs}

Methadone $\mathrm{HCl}$ (USP, Maryland, MD, USA) or dextromethorphan $\mathrm{HBr}$ (Sigma Aldrich, St. Louis, MO, USA) were dissolved in sterilized distilled water and were administered subcutaneously (s.c.) in a volume of $1.0 \mathrm{ml} / \mathrm{kg}$ of body weight.

\section{Prenatal treatment}

Pregnant Sprague-Dawley rats, weighting 200-250 g (10-12 weeks old), were assigned to four groups randomly. Each group was s.c. injected with either vehicle or $\operatorname{drug}(\mathrm{s})$ during the gestational period (E3-E20). Vehicle control group rats received distilled water, $1 \mathrm{ml} / \mathrm{kg}$ (s.c.), twice a day. Methadone-group rats received $5 \mathrm{mg} / \mathrm{kg}$ at E3 and then $7 \mathrm{mg} / \mathrm{kg}$ from E4 to E20 (s.c), twice a day. DM group rats received $3 \mathrm{mg} / \mathrm{kg}$ of DM (s.c.), twice a day. In the methadone + DM group, the rats received methadone followed by DM treatment twice a day. The offspring were weaned at day 28 after birth and housed 2-3 per cage after weaning until use. The offspring from the same dam were randomly assigned to different experiments to avoid the litter effect (the female offspring were not used in this study).

\section{Determination of natural withdrawal behaviors}

Natural withdrawal behaviors of the offspring were observed for 15 min within $24 \mathrm{~h}$ after birth. One pup was chosen randomly and removed from the dam before being placed on a white filter paper. Head moves, moving paws, rolling, stretching, twisting, and walking behaviors were observed and counted for $15 \mathrm{~min}$. There were at least 11 pups in each group.

\section{Determination of pain sensitivity of offspring on p30 and p60}

Tail-flick test: A light beam was focused on an animal's tail until that the rat flicked its tail. The recorded time was a measure of the pain threshold. The tail-flick apparatus (Columbus Instrument, Columbus, OH, USA) was used in the study. The basal latency of most rats was around 3-3.5 sec; a cutoff time of $10 \mathrm{sec}$ was used to avoid tissue damage.

Hot-plate test: In this study, a hot-plate apparatus (IITC Life Science Inc., Woodland Hills, CA, USA) was used. The animal was placed on the hot plate and the time was measured until the animal started to shake or lick its hind paw or jump from the hot plate. To avoid tissue damage, the animal was removed immediately from the metal surface after it showed pain-related behavior or reached the cutoff time (30 sec).

\section{Determination of $\mathrm{ED}_{50}$ and degree of tolerance after} sub-chronic treatment of' methadone in adult offspring The $\mathrm{ED}_{50}$ value was used as an index of the antinociceptive effect of methadone and this was determined by the up-down method [30] with the tail-flick method. Details were shown in the Additional file 1. The degree of tolerance was defined as the ratio of $\mathrm{ED}_{50}$ after sub-chronic treatment of methadone ( $4 \mathrm{mg} / \mathrm{kg}$, s.c., b.i.d. for 6 days) (day 79) and $\mathrm{ED}_{50}$ before CPP experiment and subchronic methadone treatment (day 61).

\section{Determination of the rewarding effect of methadone in} adult offspring by conditioned place preference (CPP) test In this study, we used the CPP test to evaluate methadoneinduced reward in the adult male offspring (p64-p71). Details are shown in the Additional file 1. For CPP conditioning, each rat was given saline in the morning and put in one chamber of the CPP box for $40 \mathrm{~min}$ and was given drug (methadone, $4 \mathrm{mg} / \mathrm{kg}$, s.c.) in the afternoon and put in another chamber of the CPP box for 40 min everyday for 6 days. CPP tests were performed and recorded for $15 \mathrm{~min}$ on the day before and the day after conditioning for 6 days.

\section{Water maze test}

The water maze was circular, had a diameter of $180 \mathrm{~cm}$ and a depth of $60 \mathrm{~cm}$, and was filled with water $\left(21-23^{\circ} \mathrm{C}\right)$ to a depth of $40 \mathrm{~cm}$. Spatial cues were located on the walls. The total pool was divided into 4 quadrants (NE, SE, SW, NW), which were designated as zones 1-4, 
respectively. The transparent platform $(2 \mathrm{~cm}$ below the surface of the water) was placed in the zone 1 area (NE quadrant). Rats received 5 days of training for two trials per day. The time for the animal to find the platform was recorded, and the maximal duration for each trial was 60 $\mathrm{sec}$; then the animal was put on the platform for $10 \mathrm{sec}$ to allow the animal to look around. On day 6, the platform was removed and the time the animal spent in zone 1, the previous location of the platform, was determined. All parameters were automatically recorded and analyzed by video tracking software (Etho vision, Noldus, Leesburg, VA, USA).

\section{Hippocampal LTP and LTD determination by electrophysiology}

The details of the electrophysiology recording protocol are described in the Additional file 1. Briefly, transverse $350-\mu \mathrm{m}$-thick hippocampal slices were prepared from p14-p21 male offspring using a commercial vibratome (DTK-1000, Dosaka, Kyoto, Japan). Tungsten bipolar electrodes (FHC, Bowdoin, ME, USA) were placed in the stratum radiatum of the hippocampal CA1 region to stimulate the Schaffer collateral pathway directly. Field excitatory postsynaptic potentials (fEPSPs) were recorded and analyzed offline. After $30 \mathrm{~min}$ of stable baseline recording, a high-frequency stimulation (HFS, consisting of two trains of $100 \mathrm{~Hz}$ bursts, $1 \mathrm{~s}$ in duration and with a 1 min span between the two trains) or a low-frequency stimulation (LFS, $1 \mathrm{~Hz}$ for $15 \mathrm{~min}$ ) was applied to Schaffer collaterals to induce long-term potentiation (LTP) or long-term depression (LTD) of EPSPs, respectively.

\section{Determination of expressions of mRNAs by quantitative real time RT-PCR (qPCR)}

Details of qPCR protocol are described in the Additional file 1. Briefly, total RNA was extracted from spinal cord tissue samples using TRIzol reagent (Invitrogen, Carlsbad, CA, USA). First-strand cDNA was synthesized from $1 \mu \mathrm{g}$ of the total RNA with an iScript ${ }^{\mathrm{TM}}$ cDNA Synthesis Kit (Bio-Rad Laboratories, Hercules, CA, USA). The SYBR green system (SsoFast ${ }^{\mathrm{TM}}$ EvaGreen, Bio-Rad) was used to determine the $\mathrm{Ct}$ (threshold) value. Primer sequences for
NOP receptor (Oprl1) (designed by Beacon Designer 7.6 [PREMIER Biosoft, Palo Alto, CA, USA] with NCBI reference sequence NM_031569.3), $\mu$-opioid receptor (Oprm1) and glyceraldehyde-3-phosphate dehydrogenase (Gapdh) (housekeeping gene) are presented in Table 1. A three-step run protocol was used: (i) $1 \mathrm{sec}$ at $98^{\circ} \mathrm{C}$; (ii) quantification program repeated 40 times $(1 \mathrm{sec}$ at $98^{\circ} \mathrm{C} ; 10 \mathrm{sec}$ at $57^{\circ} \mathrm{C}$ ); (iii) melting curve program $\left(70-93^{\circ} \mathrm{C}\right.$ with a heating rate of $0.5^{\circ} \mathrm{C}$ per $10 \mathrm{sec}$ ). The $\mathrm{Ct}$ value of each gene was normalized with their Gapdh. $\Delta \Delta \mathrm{Ct}=\Delta \mathrm{Ct}$ (target gene $\left._{\text {treat }}-\mathrm{GAPDH}_{\text {treat }}\right)-\Delta \mathrm{Ct}\left(\mathrm{Control}_{\text {control- }} \mathrm{GAPDH}_{\text {control }}\right)$. The fold change was measured as $2^{-\Delta \Delta C t}$.

\section{Statistical analysis}

Data are expressed as mean \pm SEM. Student $t$-test, oneway or two-way ANOVA, repeated measures one-way ANOVA, and the Newman-Keuls test or Bonferroni post-tests were used to analyze the data. A difference was considered to be significant if $\mathrm{p}<0.05$.

\section{Results}

Prenatal exposure to methadone or DM did not influence the survival rate or body weight of offspring

As shown in Figure 1A, the survival rate of offspring on day 7 after birth for the methadone, DM, and methadone + DM groups did not differ significantly from the control group $\left(\mathrm{F}_{(3,27)}=3.19 ; \mathrm{p}=0.08\right)$. The litter sizes in all tested groups were not significantly different in current study. Similarly, the body weights of all tested groups at p14 $\left(\mathrm{F}_{(3,28)}=0.47 ; \mathrm{p}=0.71\right), \mathrm{p} 30\left(\mathrm{~F}_{(3,34)}=2.30 ; \mathrm{p}=0.09\right)$, and $\mathrm{p} 60\left(\mathrm{~F}_{(3,34)}=0.006 ; \mathrm{p}=0.999\right)$ showed no significant difference (Figure 1B). These results indicate that prenatal exposure to methadone, DM, or methadone + DM at the doses in the current study did not change the survival or growth rate of offspring.

Prenatal co-administration of DM with methadone prevented the increase of natural withdrawal behaviors of offspring within $24 \mathrm{~h}$ after birth

Natural withdrawal behaviors of the offspring were shown on Table 2. We found that the total counts of natural withdrawal symptoms were significantly higher in the

Table 1 Primers for Oprl1, Oprm1 and Gapdh for qPCR

\begin{tabular}{llllll}
\hline Gene & Primer & Sequence & Position & Product (bp) & Reference \\
\hline Oprl1 & Forward & CTGGGAGGTCTTGTATGG & $268-360$ & 93 & Designed by software \\
& Reverse & CTGTGACTAGCATTGAGGA & & & [59] \\
Oprm1 & Forward & GTAGTGGGCTCTTCGGAAAC & $447-521$ & 75 & {$[60]$} \\
& Reverse & GTGGTGGCAGTCTTCATTG & & 191 & \\
Gapdh & Forward & AACGACCCCTTCATTGAC & $169-359$ & & \\
& Reverse & TCCACGACATACTCAGCAC & & & \\
\hline
\end{tabular}



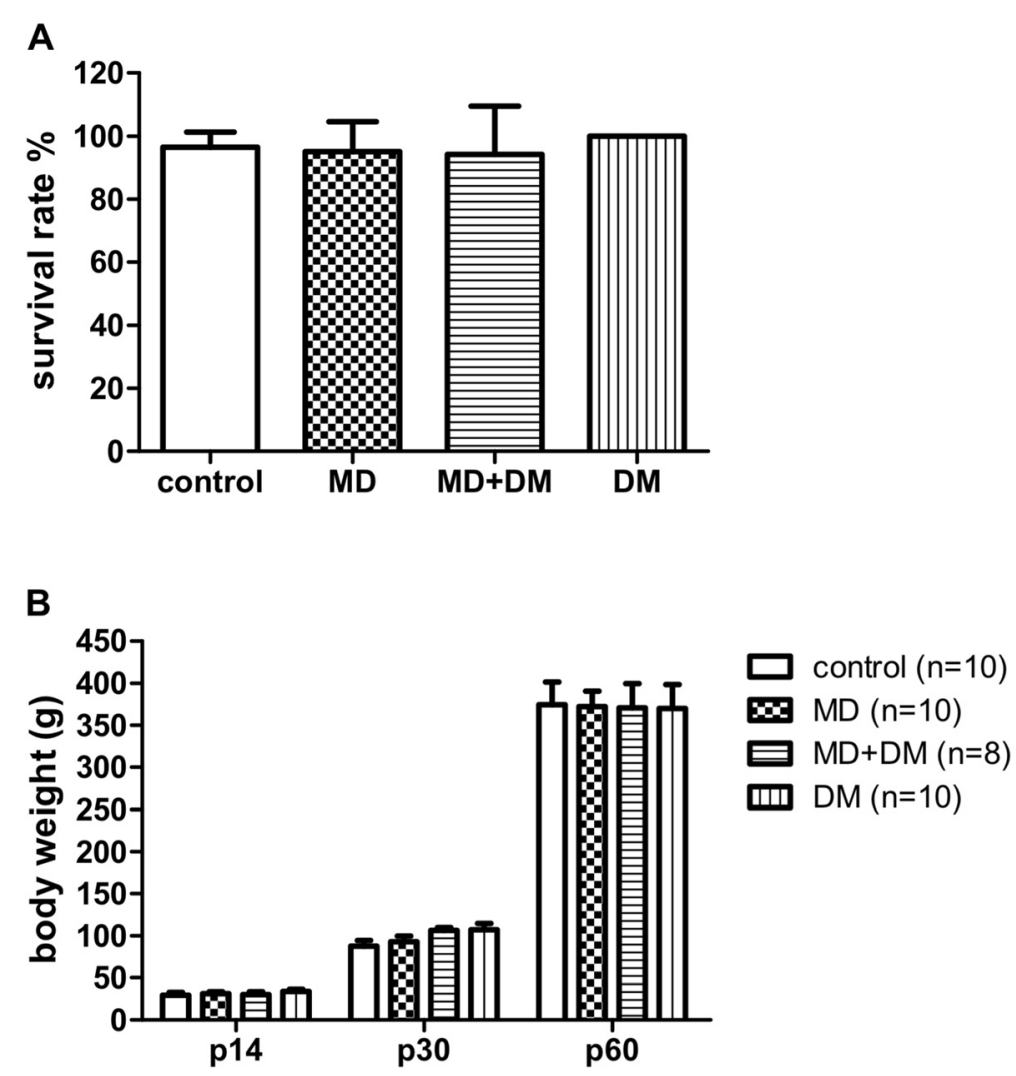

Figure 1 Prenatal exposure to methadone did not affect the survival rate and body weight. (A) The survival rate of offspring on day 7 after birth or (B) the body weight at different ages of male offspring. Data are presented as mean \pm S.E.M. $(n \geq 8)$.

methadone group $(71.8 \pm 17.8)$ than these in the control group $(17.3 \pm 4.0)$. Co-administration of DM with methadone reduced these natural withdrawal symptoms to $38.3 \pm 4.2$, which was not significantly different from that of the control group. Surprisingly, prenatal exposure to $\mathrm{DM}$ alone also increased the natural withdrawal symptoms in offspring to $60.5 \pm 14.0$, as shown on Table 2.
Prenatal methadone exposure increased the pain sensitivity of offspring, and co-administration of DM with methadone prevented this effect

Prenatal methadone-exposure significantly decreased the pain threshold of offspring determined by either tail-flick (Figure $2 \mathrm{~A})$ or hot-plate test (Figure $2 \mathrm{~B})$ on p30 $\left(\mathrm{F}_{(3,31)}=\right.$ 5.00; $\mathrm{p}<0.05)$ or $\mathrm{p} 60\left(\mathrm{~F}_{(3,29)}=2.85 ; \mathrm{p}<0.05\right)$. Prenatal exposure to DM did not alter the pain threshold of

Table 2 Natural withdrawal behaviors of offspring within $24 \mathrm{~h}$ after birth

\begin{tabular}{|c|c|c|c|c|}
\hline \multirow[b]{2}{*}{ Natural withdrawal symptoms } & Control & Methadone & Methadone + DM & DM \\
\hline & \multicolumn{4}{|c|}{ Count (Mean \pm SEM) } \\
\hline Head moves & $10.6 \pm 2.5$ & $22.8 \pm 6.7$ & $23.3 \pm 2.9$ & $44.3 \pm 11.1^{* *}$ \\
\hline Paws moving & $1.7 \pm 0.2$ & $44.8 \pm 12.5^{* * *}$ & $8.2 \pm 2.6^{\# \#}$ & $14.1 \pm 4.0^{\# \#}$ \\
\hline Stretching & $0.0 \pm 0.0$ & $0.0 \pm 0.0$ & $0.0 \pm 0.0$ & $0.17 \pm 0.17$ \\
\hline Twisting & $4.6 \pm 1.7$ & $3.2 \pm 1.1$ & $6.8 \pm 1.4$ & $0.8 \pm 0.5$ \\
\hline Rolling & $0.4 \pm 0.4$ & $0.8 \pm 0.5$ & $0.0 \pm 0.0$ & $1.3 \pm 1.0$ \\
\hline Walking & $0.0 \pm 0.0$ & $0.17 \pm 0.17$ & $0.0 \pm 0.0$ & $0.0 \pm 0.0$ \\
\hline Total score & $17.3 \pm 4.0$ & $71.8 \pm 17.8^{*}$ & $38.3 \pm 4.2$ & $60.5 \pm 14.0^{*}$ \\
\hline
\end{tabular}

Natural withdrawal behaviors of the offspring were observed and counted for 15 min within $24 \mathrm{~h}$ after birth. Data are presented as mean \pm S.E.M. ( $\mathrm{n} \geq 11$ ). Oneway ANOVA and Newman-Keuls test were used to analyze the data. ${ }^{*} \mathrm{P}<0.05,{ }^{* *} \mathrm{p}<0.01$, and ${ }^{* * *} \mathrm{p}<0.001$, compared to the control group; ${ }^{* \#} \mathrm{p}<0.01$, compared to the methadone group. 

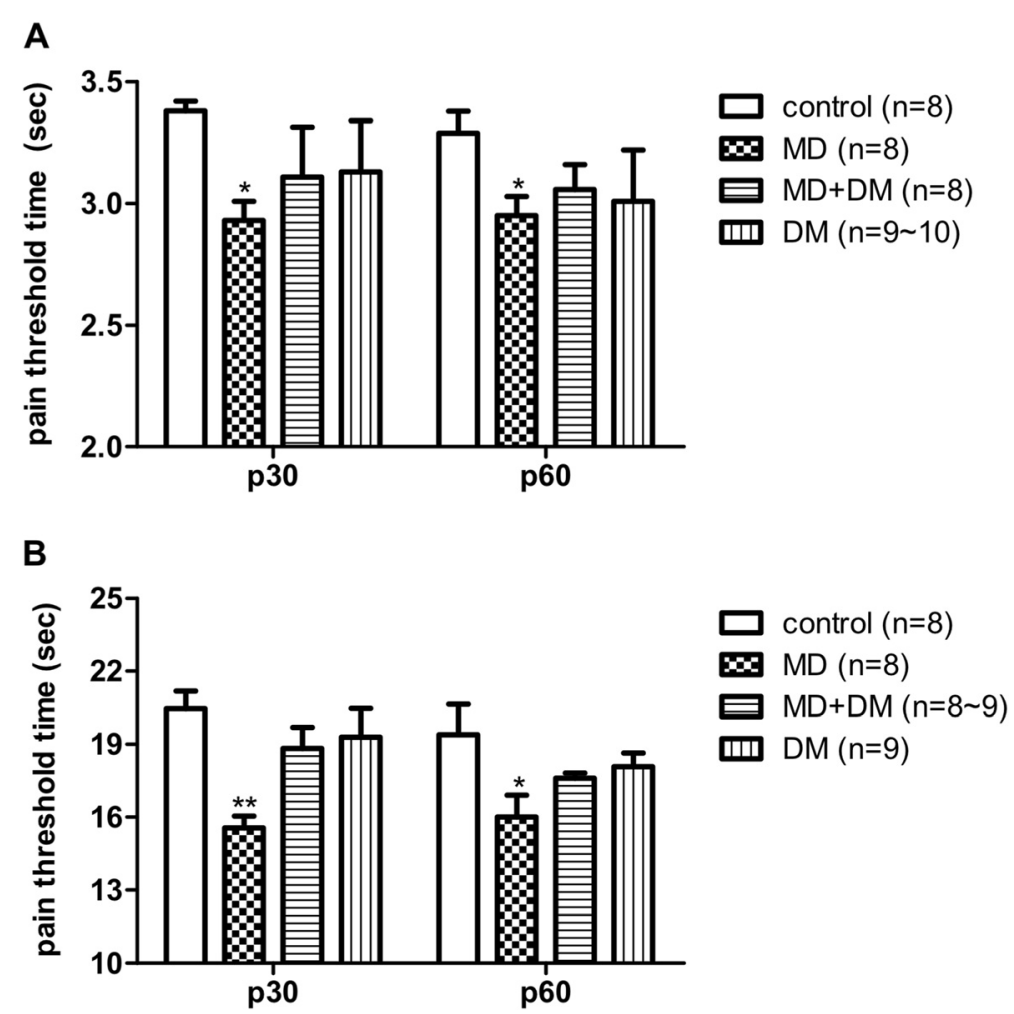

Figure 2 The effects of pain threshold in prenatal drug exposure male offspring. Prenatal exposure to methadone (MD) decreased the pain threshold at different ages (p30 or p60) in male offspring and prenatal co-administration of methadone and dextromethorphan (MD + DM) prevented this effect. Acute heat nociceptive responses were determined by $(\mathbf{A})$ tail-flick test and $\mathbf{( B )}$ hot-plate test. Data are presented as mean \pm S.E.M. $(n \geq 8) .{ }^{*} P<0.05$ and ${ }^{* *} p<0.01$ when compared to the control group.

offspring significantly. However, prenatal exposure of DM in conjunction with methadone from E3-E20, prevented the changes induced by prenatal methadone exposure alone either partially or completely in the tail flick and hot plate tests, respectively.

\section{The mRNA levels of pain-related receptors in the spinal cord of male offspring}

In order to reveal the possible mechanisms by which prenatal methadone affects pain sensitivity, we investigated the gene expression of $\mu$-opioid receptors (MOR) and nociceptin/orphanin FQ receptors (NOPR) in the spinal cord of male offspring. Our results showed that prenatal exposure to methadone caused a significant decrease in the gene expression (mRNA level) of $\operatorname{MOR}\left(\mathrm{F}_{(3,28)}=\right.$ 56.35; $\mathrm{p}<0.001)$ and $\operatorname{NOPR}\left(\mathrm{F}_{(3,28)}=60.53 ; \mathrm{p}<0.001\right)$ (Figure $3 \mathrm{~A}$ and $\mathrm{B}$ ). In the results of prenatal exposure to DM alone, there were also slight but significant decreases in the mRNA levels of MOR and NOPR. However, co-administration of DM with methadone in the maternal rats significantly prevented the decrease in mRNA levels of these two pain-related receptors in the spinal cord of offspring induced by prenatal methadone exposure.

\section{Rewarding effects of methadone in male adult offspring}

The CPP test was used to determine the rewarding effect of methadone in the offspring. We found that when methadone $(4 \mathrm{mg} / \mathrm{kg}$, s.c.) was given once daily and conditioned for 6 days, it significantly increased the preference time for the drug-paired compartment in all groups tested $\left(\mathrm{F}_{(3,68)}=6.59 ; \mathrm{p}<0.001\right)$ (post-condition vs. pre-condition, Figure 4). However, methadone-induced CPP in the prenatal methadone-exposed group was significantly higher than that of the control group. Co-administration of DM with methadone in the maternal rats significantly prevented this higher rewarding effect and the higher addiction potential of methadone in the offspring, as shown in Figure $4\left(\mathrm{~F}_{(3,34)}=11.89 ; \mathrm{p}<0.001\right)$.

\section{Sub-chronic treatment with methadone in offspring} induced tolerance, which was not affected by prenatal co-administration of DM with methadone

According to the results shown in Figure 2, prenatal exposure of methadone decreased the pain threshold (i.e. increased the pain sensitivity). In this study, the methadone-induced tolerance was measured in offspring of all groups. As shown on Table 3, the $\mathrm{ED}_{50}$ of 

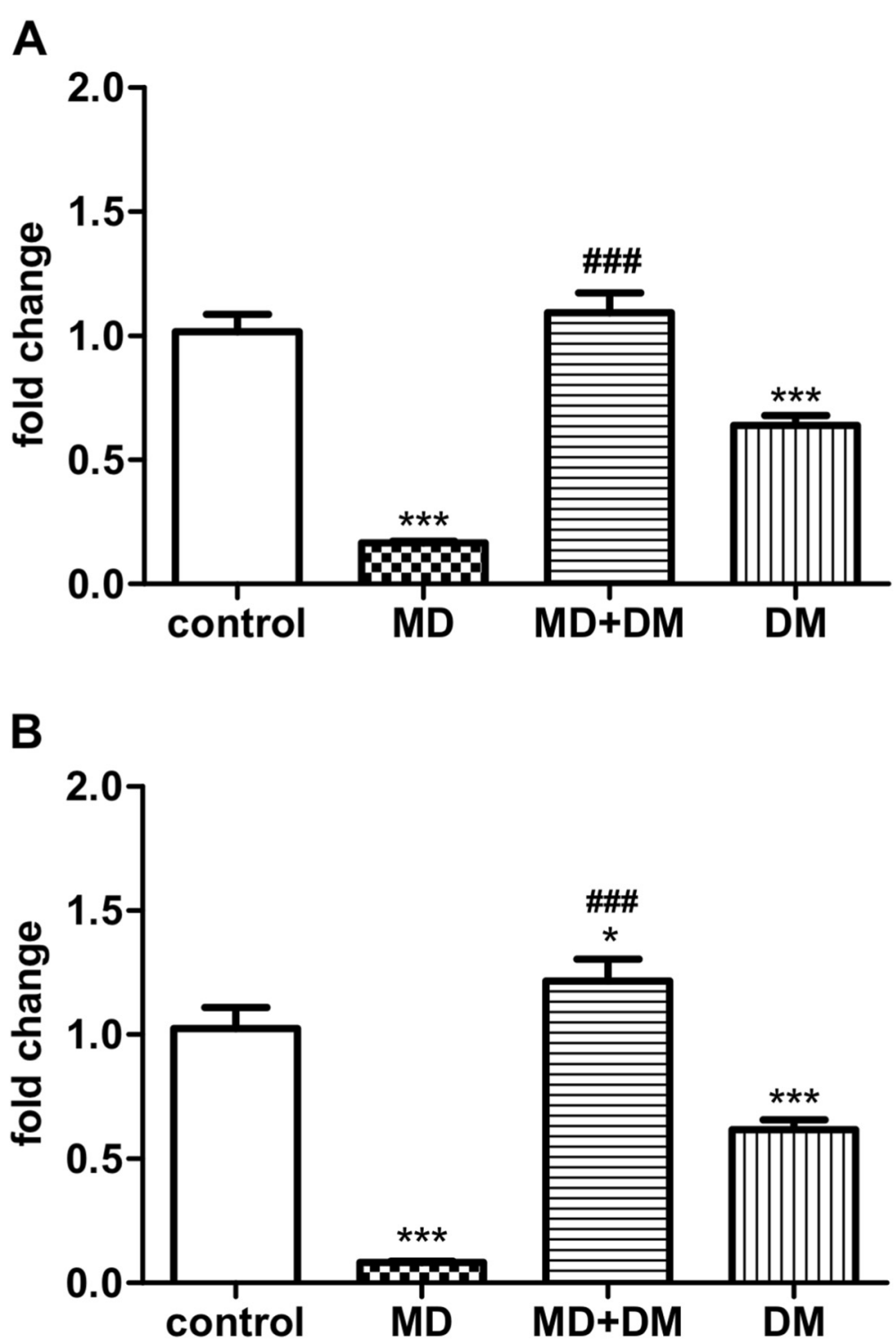

Figure 3 The mRNA expression of pain-related opioid receptors in the spinal cord of offspring. The mRNA level of (A) mu-opioid receptor (MOR); and (B) nociceptin receptor (NOPR); in the spinal cord of prenatal drug(s) exposed male offspring at P30. Data are presented as mean \pm S.E.M. $(n \geq 8)$. ${ }^{*} P<0.05$, ${ }^{* *} p<0.01$ and ${ }^{* * *} P<0.001$ when compared to the control group; \#\#\#p 0.001 when compared to the methadone (MD) group.

all the groups before the CPP experiment were similar $(1.58-1.77 \mathrm{mg} / \mathrm{kg})$. After the CPP experiment and subchronic treatment of methadone, the $\mathrm{ED}_{50}$ of all the groups increased 1.34-1.84-fold, as shown on Table 3. However, there were no significant differences among the groups regarding the $\mathrm{ED}_{50}$ after sub-chronic methadone administration.

Prenatal exposure with methadone or DM did not influence the spatial memory of male offspring, as determined by the water maze test

A water maze was utilized to test the spatial learning and memory in prenatal methadone-exposed offsprings.
We found no difference in the water maze test among all groups tested (Figure 5A and B). As shown in Figure 5A, the learning rate during the five days of training was simi$\operatorname{lar}\left(\mathrm{F}_{(3,325)}=0.66 ; \mathrm{p}=0.9226\right)$ and there was also no significant difference for time spent in the platform quadrant (without platform) on day $6\left(\mathrm{~F}_{(3,65)}=0.89 ; \mathrm{p}=0.45\right)$ (Figure 5B) in all groups. Long-term potentiation (LTP) and long-term depression (LTD) were determined for the possible neuronal mechanisms of memory formation using hippocampal slices of prenatal methadoneor vehicle-exposed offspring (p14-p21). As shown in Figure 6, there was no significant difference between these two groups for LTP $(\mathrm{p}=0.511)$ or LTD $(\mathrm{p}=0.753)$. 


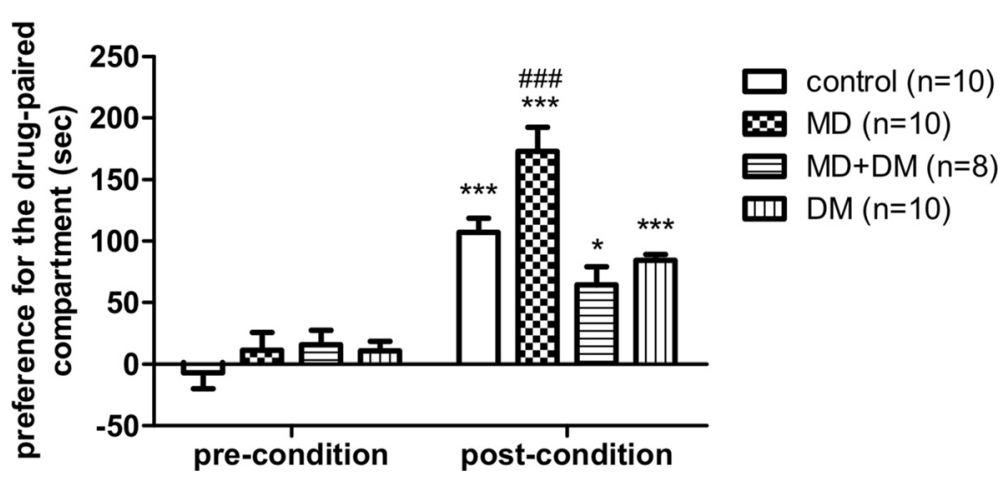

Figure 4 Postnatal methadone-induced rewarding effects on prenatal methadone or DM exposed offspring. Rewarding effects induced by methadone (MD, 6 conditioning at $4 \mathrm{mg} / \mathrm{kg}$, s.c.) in male adult offspring. Data are presented as mean \pm S.E.M. $(n \geq 8) .{ }^{*} P<0.05$ and ${ }^{* * *} p<0.001$ when compared to pre-conditioning data of its own group; $\#$ \#\# 0.001 when compared to post-conditioning data of the control group.

\section{Discussion}

The goal of this study is to evaluate the effects of coadministration of DM with methadone in the prenatal stage on offspring $[21,29,31]$. The doses we used are within the clinical therapeutic ranges converted to rats based on the body surface area. Seven $\mathrm{mg} / \mathrm{kg}$ methadone for rats is approximately $70 \mathrm{mg}$ methadone for $70 \mathrm{~kg} \mathrm{hu}$ man; and $3 \mathrm{mg} / \mathrm{kg}$ DM for rats is about $30 \mathrm{mg}$ for $70 \mathrm{~kg}$ human. In the present study, the findings indicate that DM treatment with methadone in the prenatal stage could prevent or suppress methadone-induced behavioral abnormality in the offspring. Furthermore, the effects of prenatal exposure to methadone to decrease the mRNA levels of MOR and NOPR in the spinal cord of offspring were also prevented by co-administration of DM with methadone in the maternal rats. Prenatal methadone did not affect learning or spatial memory in the offspring or the LTP or LTD of hippocampal slices of the prenatal methadone-exposed offspring.

The survival rate and body weights of offspring in methadone group were not different from those of the vehicle control group. Prenatal exposure to DM or methadone + DM at the doses we used did not change the survival rate or body weight of offspring (Figure 1).

Table 3 Methadone-induced tolerance in male offspring

\begin{tabular}{llll}
\hline \multirow{2}{*}{$\begin{array}{l}\text { Prenatal } \\
\text { treated }\end{array}$} & \multicolumn{2}{c}{$\mathrm{ED}_{50}$ (mg/kg) } & \\
\cline { 2 - 4 } & Before-CPP & $\begin{array}{l}\text { After-chronic } \\
\text { treatment }\end{array}$ & $\begin{array}{l}\text { Degree of tolerance } \\
\text { (after-chronic/ } \\
\text { before-CPP) }\end{array}$ \\
\hline Control & $1.77 \pm 0.13$ & $2.46 \pm 0.13^{* *}$ & 1.34 \\
Methadone & $1.77 \pm 0.13$ & $3.08 \pm 0.13^{* * *}$ & 1.74 \\
Methadone + DM & $1.78 \pm 0.13$ & $3.28 \pm 0.18^{* * *}$ & 1.84 \\
DM & $1.58 \pm 0.18$ & $2.46 \pm 0.13^{*}$ & 1.56 \\
\hline
\end{tabular}

Tail-flick test and up-down method were used to determine the $\mathrm{ED}_{50}$. Data are presented as mean \pm S.E.M. $(n \geq 6)$. Two-way ANOVA and Bonferroni post-tests were used to analyze the data. ${ }^{*} \mathrm{P}<0.05$, ${ }^{* *} \mathrm{p}<0.01$, and ${ }^{* * *} \mathrm{p}<0.001$, compared to the data before CPP of its own group.
Furthermore, we did not observe the dams in the groups behaving abnormally during their pregnancy or breeding period. These results may rule out the possible effects of nutrition, doses of methadone, and maternal care on the behavioral changes of offspring. Therefore, the preventive effects of DM on prenatal methadone-induced behavioral or biochemical changes could be explained by its pharmacologic actions.

The changes in pain sensitivity in prenatal methadoneexposed animals might be because methadone changes the expression of opioid receptors. MOR and NOPR are expressed early in the brain and spinal cord at the embryonic stage [32,33]. These findings suggest that MOR and NOPR may be easily influenced by prenatal opioid exposure. Besides, the expressions of opioid receptors in the central nervous system may exhibit a region specific character in the intrauterine opioid-exposed animals. An early study showed that prenatal methadone administration induced sustained decreases in the expression of both delta- $(\delta-)$ and $\mu$-opioid receptors in the hypothalamus but not in the cerebral cortex [34]. Another study by Darmani et al. [35] exhibited non-significant changes in the expression of MOR, but reducing its binding affinity to methadone in the whole brain homogenate of prenatal methadone-exposed rat offspring. Recently, Chiang et al. [36], also showed that expressions of MOR and NOPR were not different in the nucleus accumbens of prenatal methadone-exposed rats at their adulthood as compared with their control mates. In the current study, we found a significant decrease in the mRNA expression of MOR and NOPR in the spinal cord of prenatal methadone-exposed offspring at p30 and meanwhile, the pain sensitivity of offspring is increased. It has been know that the peptide of nociceptin/orphanin FQ (N/OFQ) acts on the NOPR and also serves as a pain modulator in the central nervous system [37]. N/OFQ and NOPR are highly presented in the dorsal part of the spinal cord $[37,38]$ and the pain-modulated function of N/OFQ in spinal cord is 


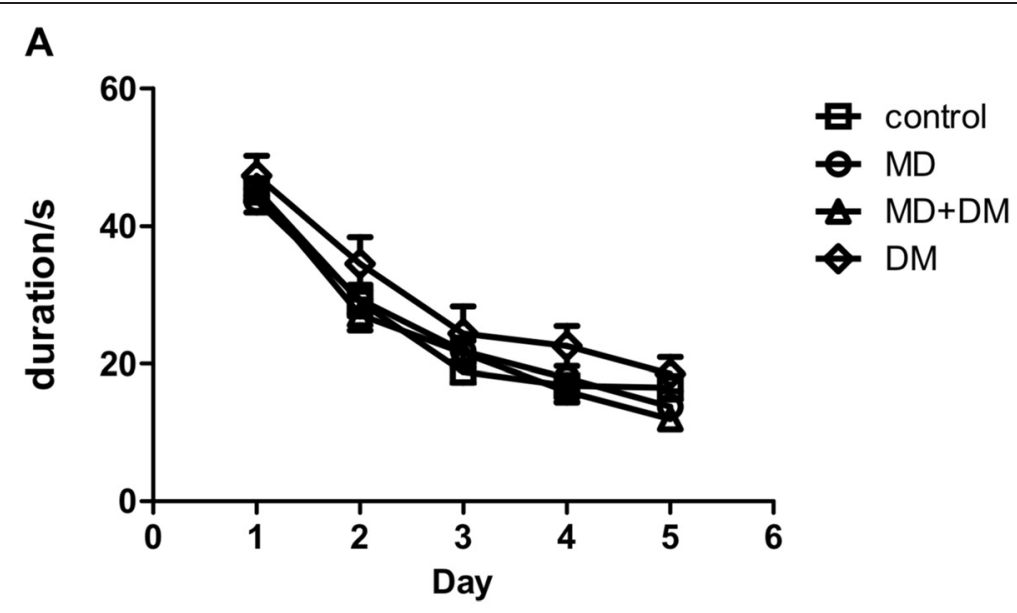

B

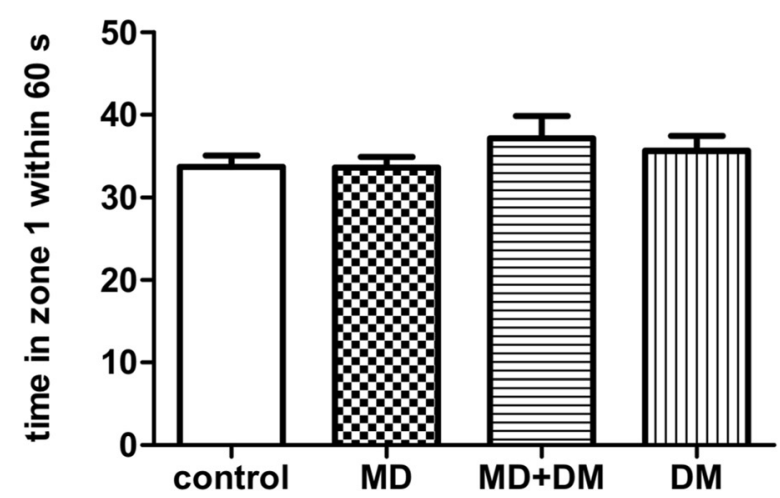

Figure $\mathbf{5}$ The effects of prenatal drug exposure on spatial learning and memory of male offspring. Prenatal exposure to methadone did not affect spatial learning and memory of male offspring determined by water maze test. (A) Water maze training with platform from day 1 to day 5; (B) water maze test without platform on day 6. Data were presented as mean \pm S.E.M. ( $\mathrm{n} \geq 12$ ).
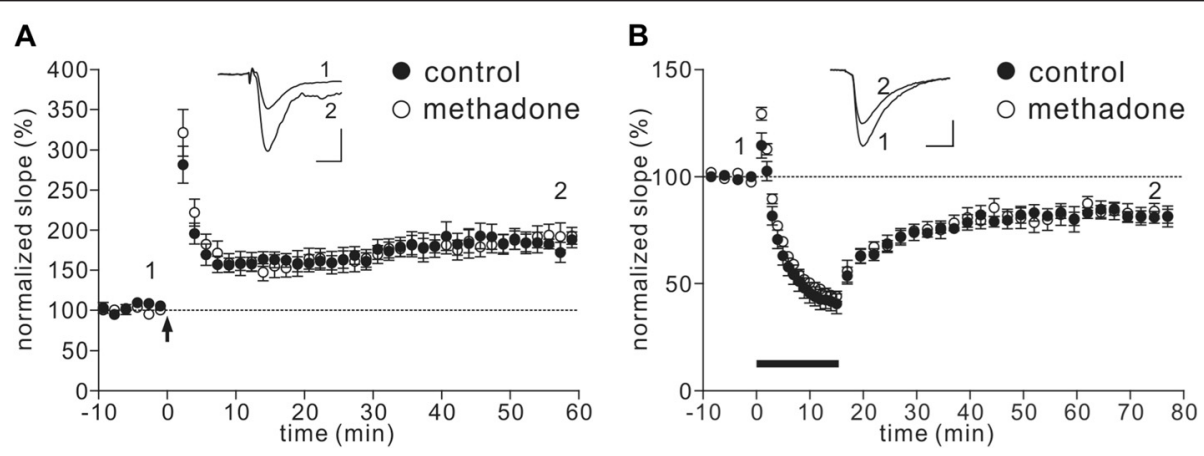

Figure 6 Changes of LTP and LTD in the prenatal methadone- or DM-exposed offspring. Prenatal methadone did not change the hippocampal LTP or LTD in p14-p21 rats. Time courses of normalized slopes of fEPSPs during (A) LTP and (B) LTD experiments are shown. A high-frequency stimulation (HFS) protocol (A) or a low-frequency stimulation (LFS) protocol (B) was applied at 0 min (arrow) to hippocampal slice of p14-p21 offspring born from control (black circle, $n \geq 8$ ) or methadone (hollow circle, $n \geq 7$ ) treated maternal rats. Representative traces of fEPSP from one control slice before HFS (1) and 55 min after HFS (2) are shown in the top middle of (A), and another representative traces of fEPSP from one control before (1) and $60 \mathrm{~min}$ after (2) LFS are shown in the top middle of (B). Scale bar, $100 \mu \mathrm{V}, 10 \mathrm{~ms}$. 
similar with MOR endogenous ligand-endorphins $[39,40]$. Endorphins can act on the MOR and produce antinociceptive function in the spinal cord [40]. Early studies also showed that intrathecal administration of N/OFQ causes the antinociceptive effect in the monkey and rodents $[37,38]$. Both of MOR and NOPR could be influenced on expression or affinity by chronic administration of exogenous opioids [41,42]. Several studies have been shown to cross influence another type of opioid receptors when continued activation of one type of opioid receptors. For example, chronic treatment with kappa- ( $\mathrm{\kappa}-$ ) opioid receptor agonist, U50,448H, decreased the expression of both $\kappa$ - and $\delta$ - opioid receptors in the spinal cord and striatum of rats [43]. It has also been shown that chronic morphine influenced the N/OFQ systems [42,44]. Previous studies also provided evidence that NOPR and MOR not only formed a heterodimer with each other, but also regulated the desensitization function with each other [45-47]. Formation of NOPR/MOR heterodimer selectively induced cross-desensitization of MOR and impaired the potency of DAMGO-induced adenylate cyclase inhibition and p42/p44 (MAPK) phosphorylation [46]. Furthermore, Mandyam et al. [45] found that the PKC signals may be a cross-talk mechanism for NOPR/MOR heterodimer.

On the other hand, although our results showed that the mRNA of NOPR and MOR were also reduced in the spinal cord of prenatal DM-exposed rats, the pain sensitivity did not show significant change in this group of animals. These results imply a complicated cross-talk of cellular signaling to behavioral expression and need further exploration. In a brief summary, the increase of pain sensitivity in the prenatal methadone-exposed animals may be partly due to the reduction of both NOPRand MOR-related signals.

Besides pain regulation, prenatal opioid-exposed offspring might also change their reward sensitivity to opioids, such as offspring from morphine-addicted mother becoming more sensitive to morphine-induced reward [48,49]. In this current study, prenatal methadone-exposed offspring showed higher reward than offspring from other groups after conditioning with $4 \mathrm{mg} / \mathrm{kg}$ methadone for 6 days. This implies that the offspring from methadonetreated mothers may more easily become addicted to methadone later in their life than others.

Several studies have found that the NAS of offspring was related to the dose of methadone used in the mother $[18,19,50]$. A higher dose of methadone exposure in prenatal stage caused more serious NAS and increased frequency of morphine treatment in the hospital. The doses of methadone we used in the present study also induced certain natural withdrawal behaviors but not very serious (only "paws moving"). We also found that prenatal exposure to DM alone also increased natural withdrawal behaviors slightly. However, co-administration of DM with methadone in the maternal rats reduced these natural withdrawal behaviors of neonates to similar scores of the control group (Table 2).

Recently, the relationship between NMDA receptors and opioid systems has been studied. Morphine tolerance could be attenuated by resveratrol via inhibiting neuroinflammation and down-regulating the expression of NR1 and NR2B subunit of NMDA receptors [51]. Morphine-induced up-regulated state of NR3B in lymphocytes could also be reduced after subjects entered a methadone maintenance program [52]. This indicates that NMDA receptors play an important role to regulate opioid-induced effects and are involved in the opioidaddiction process in both humans and animals [53]. Since both methadone (racemic mixture) and DM have been shown to have NMDA receptor antagonist property $[9,21]$, we think that blocking of NMDA receptors by methadone or DM may be involved in the increase of natural withdrawal behaviors of offspring. There was a human case report which showed DM caused withdrawal syndromes with over 10 folds ( $1800 \mathrm{mg} /$ daily) of therapeutic dose [54]. However there is no evidence showed that the NAS has exhibited in prenatal-exposed infants within the therapeutic dose ranges of DM.

Compared with our previous prenatal morphine-exposed studies $[28,31]$, methadone seems to show less adverse effects than morphine in these intrauterine exposed rats. This may be due to the NMDA receptor antagonist property of methadone. Chronic morphine administration affected the binding properties and EPSCs of NMDA receptors in the hippocampus of offspring [31,55]. It has also been shown that prenatal exposure to morphine leads to memory problems in offspring [56-58]. However, no change regarding the spatial memory or hippocampal LTP/ LTD was found in prenatal methadone-exposed rats in the current study. Although suppression of NMDA receptor activities could influence the development of neurons, over-activation of the NMDA receptors through chronic activation of opioid system may also cause serious neurotoxicity in offspring or lead to other defects in them. The excess activity of NMDA receptors induced by chronic opioid (morphine or methadone) may be counterbalanced by DM or methadone itself, so that the preventative effects of DM and less-adverse effects of methadone upon the offspring could be seen. In fact, offspring exposure to DM alone in the intrauterine stage decreased the mRNA expressions of MOR and NOPR in the spinal cord, which may also be due to blocking of the normal function of NMDA receptors.

\section{Conclusion}

In summary, this study showed that co-administration of DM with methadone in the maternal rats significantly decreased the effects of prenatal methadone on pain 
sensitivity, natural withdrawal, and reward in the offspring. In conclusion, this study reveals that DM may have great potential to be used in combination with methadone maintenance therapy in pregnant heroin abusers to reduce the side effects of methadone on the offspring.

\section{Additional file}

Additional file 1: Detailed methods of $\mathrm{ED}_{50}$, degree of tolerance, water maze, QPCR and electrophysiology.

\section{Abbreviations}

CPP: Conditioned place preference; DM: Dextromethorphan; fEPSPs: Field excitatory postsynaptic potentials; HFS: High-frequency stimulation; LFS: Low-frequency stimulation; MAPK: Mitogen-activated protein kinase; MOR: $\mu$-opioid receptor; NAS: Neonatal abstinence syndrome; N/OFQ: Nociceptin/orphanin FQ; NMDA: N-methyl-D-aspartate; NOPR: Nociceptin receptor; QPCR: Quantitative real-time PCR.

\section{Competing interests}

The authors declare that they have no competing interests.

\section{Authors' contributions}

YCC established the animal model and drafted the manuscript. LCY, KYH, CWL, TWH, and WJL performed the experiments and analyzed the data. IKH, and PLT conceived the study and revised the final manuscript. PLT was in charge of all the studies. All authors have critically reviewed the content and approved the final version for publication.

\section{Acknowledgments}

We thank Mr. M. Swofford for English editing before submission of the paper. The work was supported by the National Health Research Institutes (PH-100-PP-53; PH-101-PP-33; NHRI-EX104-10224NC; NHRI-103A1-PDCO-1312141) and China Medical University Hospital (DMR-104-025) in Taiwan.

\section{Author details \\ ${ }^{1}$ Center for Drug Abuse and Addiction, China Medical University Hospital, Taichung, Taiwan. ${ }^{2}$ Graduate Institute of Clinical Medical Science, China Medical University, Taichung, Taiwan. ${ }^{3}$ Department of Pharmacology, National Defense Medical Center, Taipei, Taiwan. ${ }^{4}$ Center for Neuropsychiatric Research, National Health Research Institutes, Zhunan, Miaoli County, Taiwan.}

Received: 20 October 2014 Accepted: 5 March 2015

Published online: 20 March 2015

\section{References}

1. Joseph H, Stancliff S, Langrod J. Methadone maintenance treatment (MMT): a review of historical and clinical issues. Mt Sinai J Med. 2000;67(5-6):347-64.

2. Goldstein A. Heroin addiction: neurobiology, pharmacology, and policy. J Psychoactive Drugs. 1991;23(2):123-33.

3. Lobmaier P, Gossop M, Waal H, Bramness J. The pharmacological treatment of opioid addiction-a clinical perspective. Eur J Clin Pharmacol. 2010;66(6):537-45. doi:10.1007/s00228-010-0793-6.

4. SAMHSA. Results from the 2010 National Survey on Drug Use and Health: Summary of National Findings. 2011.

5. Yanai J, Huleihel R, Izrael M, Metsuyanim S, Shahak H, Vatury O, et al. Functional changes after prenatal opiate exposure related to opiate receptors' regulated alterations in cholinergic innervation. Int I Neuropsychopharmacol. 2003;6(3):253-65. doi:10.1017/\$1461145703003523.

6. The impact of intrauterine exposure versus postnatal environment in neurodevelopmental toxicity: long-term neurobehavioral studies in children at risk for developmental disorders. Toxicol Lett. 2003;140-141:171-81. doi:S0378427402005052

7. Byrnes JJ, Babb JA, Scanlan VF, Byrnes EM. Adolescent opioid exposure in female rats: transgenerational effects on morphine analgesia and anxiety-like behavior in adult offspring. Behav Brain Res. 2011;218(1):200-5. doi:10.1016/j.bbr.2010.11.059.
8. Chiang YC, Hung TW, Lee CW, Yan JY, Ho IK. Enhancement of tolerance development to morphine in rats prenatally exposed to morphine, methadone, and buprenorphine. J Biomed Sci. 2010;17:46. doi:10.1186/1423-0127-17-46.

9. Trescot AM, Datta S, Lee M, Hansen H. Opioid pharmacology. Pain Physician. 2008;11(2 Suppl):S133-53.

10. Pritham UA, Troese M, Stetson A. Methadone and buprenorphine treatment during pregnancy: what are the effects on infants? Nurs Womens Health. 2007;11(6):558-67. doi:10.1111/j.1751-486X.2007.00243.x.

11. Brown HL, Britton KA, Mahaffey D, Brizendine E, Hiett AK, Turnquest MA. Methadone maintenance in pregnancy: a reappraisal. Am J Obstet Gynecol. 1998;179(2):459-63.

12. Hulse GK, Milne E, English DR, Holman CD. Assessing the relationship between maternal opiate use and neonatal mortality. Addiction. 1998;93(7):1033-42.

13. Farid WO, Dunlop SA, Tait RJ, Hulse GK. The effects of maternally administered methadone, buprenorphine and naltrexone on offspring: review of human and animal data. Current Neuropharmacology. 2008;6(2):125-50. doi:10.2174/157015908784533842.

14. Pierson PS, Howard P, Kleber HD. Sudden deaths in infants born to methadone-maintained addicts. Jama. 1972;220(13):1733-4.

15. Katzung BG. Basic \& clinical pharmacology. 8th ed. New York: Lange Medical Books/McGraw-Hill; 2001

16. Wang SC, Ho IK, Wu SL, Liu SC, Kuo HW, Lin KM, et al. Development of a method to measure methadone enantiomers and its metabolites without enantiomer standard compounds for the plasma of methadone maintenance patients. Biomedical Chromatography : BMC. 2010;24(7):782-8. doi:10.1002/bmc.1363.

17. Kennedy AP, Phillips KA, Epstein DH, Reamer DA, Schmittner J, Preston KL. A randomized investigation of methadone doses at or over $100 \mathrm{mg} /$ day, combined with contingency management. Drug Alcohol Depend. 2013;130(1-3):77-84. 10.1016/j.drugalcdep.2012.10.025.

18. Dashe JS, Sheffield JS, Olscher DA, Todd SJ, Jackson GL, Wendel GD. Relationship between maternal methadone dosage and neonatal withdrawal. Obstet Gynecol. 2002;100(6):1244-9. doi:S0029784402023876.

19. Liu AJ, Jones MP, Murray H, Cook CM, Nanan R. Perinatal risk factors for the neonatal abstinence syndrome in infants born to women on methadone maintenance therapy. Aust N Z J Obstet Gynaecol. 2010;50(3):253-8. doi:10.1111/j.1479-828X.2010.01168.x.

20. Sharpe C, Kuschel C. Outcomes of infants born to mothers receiving methadone for pain management in pregnancy. Arch Dis Child Fetal Neonatal Ed. 2004;89(1):F33-6.

21. Shin EJ, Bach JH, Lee SY, Kim JM, Lee J, Hong JS, et al. Neuropsychotoxic and neuroprotective potentials of dextromethorphan and its analogs. J Pharmacol Sci. 2011;116(2):137-48.

22. Rossi S, Daniele I, Bastrenta P, Mastrangelo M, Lista G. Early myoclonic encephalopathy and nonketotic hyperglycinemia. Pediatr Neurol. 2009:41(5):371-4. doi:10.1016/.jpediatrneurol.2009.05.005.

23. Hamosh A, McDonald JW, Valle D, Francomano CA, Niedermeyer E, Johnston MV. Dextromethorphan and high-dose benzoate therapy for nonketotic hyperglycinemia in an infant. J Pediatr. 1992;121(1):131-5.

24. Martinez-Frias ML, Rodriguez-Pinilla E. Epidemiologic analysis of prenatal exposure to cough medicines containing dextromethorphan: no evidence of human teratogenicity. Teratology. 2001;63(1):38-41. doi:10.1002/1096-9926 (200101)63:1<38::AID-TERA1006>3.0.CO;2-6.

25. Huang EY, Liu TC, Tao PL. Co-administration of dextromethorphan with morphine attenuates morphine rewarding effect and related dopamine releases at the nucleus accumbens. Naunyn Schmiedebergs Arch Pharmacol. 2003:368(5):386-92. doi:10.1007/s00210-003-0803-7.

26. Lue WM, Huang EY, Yang SN, Wong CS, Tao PL. Post-treatment of dextromethorphan reverses morphine effect on conditioned place preference in rats. Synapse. 2007;61(6):420-8. doi:10.1002/syn.20391.

27. Wu LY, Huang EY, Tao PL. Coadministration of dextromethorphan during pregnancy and throughout lactation prevents morphine-induced hyperprolactinemia in female rats. Fertil Steril. 2010;93(5):1686-94. doi:10.1016/j.fertnstert.2009.01.143.

28. Yeh GC, Tao PL, Chen JY, Lai MC, Gao FS, Hu CL. Dextromethorphan attenuates morphine withdrawal syndrome in neonatal rats passively exposed to morphine. Eur J Pharmacol. 2002;453(2-3):197-202.

29. Tao PL, Chen CF, Huang EY. Dextromethorphan attenuated the higher vulnerability to inflammatory thermal hyperalgesia caused by prenatal morphine exposure in rat offspring. J Biomed Sci. 2011;18:64. doi:10.1186/1423-0127-18-64. 
30. Dixon WJ. Staircase bioassay: the up-and-down method. Neurosci Biobehav Rev. 1991;15(1):47-50.

31. Tao PL, Yeh GC, Su CH, Wu YH. Co-administration of dextromethorphan during pregnancy and throughout lactation significantly decreases the adverse effects associated with chronic morphine administration in rat offspring. Life Sci. 2001;69(20):2439-50.

32. Rahman W, Dashwood MR, Fitzgerald M, Aynsley-Green A, Dickenson AH. Postnatal development of multiple opioid receptors in the spinal cord and development of spinal morphine analgesia. Brain Res Dev Brain Res. 1998;108(1-2):239-54.

33. Neal Jr CR, Akil H, Watson Jr SJ. Expression of orphanin FQ and the opioid receptor-like (ORL1) receptor in the developing human and rat brain. J Chem Neuroanat. 2001;22(4):219-49.

34. Wang C, Pasulka P, Perry B, Pizzi WJ, Schnoll SH. Effect of perinatal exposure to methadone on brain opioid and alpha 2-adrenergic receptors. Neurobehav Toxicol Teratol. 1986;8(4):399-402.

35. Darmani NA, Schnoll SH, Pandey U, Martin BR. Chronic prenatal methadone exposure alters central opioid mu-receptor affinity in both fetal and maternal brain. Neurotoxicol Teratol. 1992;14(4):265-71. doi:0892-0362(92)90006-V.

36. Chiang YC, Hung TW, Ho IK. Development of sensitization to methamphetamine in offspring prenatally exposed to morphine, methadone and buprenorphine. Addict Biol. 2014;19(4):676-86. doi:10.1111/adb.12055.

37. Tian JH, Xu W, Fang Y, Mogil JS, Grisel JE, Grandy DK, et al. Bidirectional modulatory effect of orphanin FQ on morphine-induced analgesia: antagonism in brain and potentiation in spinal cord of the rat. Br J Pharmacol. 1997;120(4):676-80. doi:10.1038/sj.bjp.0700942.

38. Ko MC, Naughton NN. Antinociceptive effects of nociceptin/orphanin FQ administered intrathecally in monkeys. J Pain. 2009;10(5):509-16. doi:10.1016/j.jpain.2008.11.006.

39. Spetea M, Asim MF, Wolber G, Schmidhammer H. The micro opioid receptor and ligands acting at the micro opioid receptor, as therapeutics and potential therapeutics. Curr Pharm Des. 2013;19(42):7415-34.

40. Wu XN, Zhang T, Qian NS, Guo XD, Yang HJ, Huang KB, et al. Antinociceptive effects of endomorphin-2: Suppression of substance $P$ release in the inflammatory pain model rat. Neurochem Int. 2015;82C:1-9. doi:10.1016/j.neuint.2015.01.004

41. Sprouse-Blum AS, Smith G, Sugai D, Parsa FD. Understanding endorphins and their importance in pain management. Hawaii Med J. 2010;69(3):70-1.

42. Zhang Y, Donica CL, Standifer KM. Sex differences in the Nociceptin/Orphanin FQ system in rat spinal cord following chronic morphine treatment. Neuropharmacology. 2012;63(3):427-33. doi:10.1016/j.neuropharm.2012.04.028.

43. Bhargava HN, Gulati A, Ramarao P. Effect of chronic administration of $U-50,488 \mathrm{H}$ on tolerance to its pharmacological actions and on multiple opioid receptors in rat brain regions and spinal cord. J Pharmacol Exp Ther. 1989;251(1):21-6.

44. Ueda H, Inoue M, Takeshima H, Iwasawa Y. Enhanced spinal nociceptin receptor expression develops morphine tolerance and dependence. J Neurosci. 2000;20(20):7640-7.

45. Mandyam CD, Thakker DR, Christensen JL, Standifer KM. Orphanin FQ/nociceptinmediated desensitization of opioid receptor-like 1 receptor and mu opioid receptors involves protein kinase C: a molecular mechanism for heterologous cross-talk. J Pharmacol Exp Ther. 2002;302(2):502-9. doi:10.1124/jpet.102.033159.

46. Wang HL, Hsu CY, Huang PC, Kuo YL, Li AH, Yeh TH, et al. Heterodimerization of opioid receptor-like 1 and mu-opioid receptors impairs the potency of micro receptor agonist. J Neurochem. 2005;92(6):1285-94. doi:10.1111/j.1471-4159.2004.02921.X.

47. Lee CW, Yan JY, Chiang YC, Hung TW, Wang HL, Chiou LC, et al. Differential pharmacological actions of methadone and buprenorphine in human embryonic kidney 293 cells coexpressing human mu-opioid and opioid receptor-like 1 receptors. Neurochem Res. 2011;36(11):2008-21. doi:10.1007/s11064-011-0525-z.

48. Wu LY, Chen JF, Tao PL, Huang EY. Attenuation by dextromethorphan on the higher liability to morphine-induced reward, caused by prenatal exposure of morphine in rat offspring. J Biomed Sci. 2009;16:106. doi:10.1186/1423-0127-16-106.

49. Gagin R, Cohen E, Shavit Y. Prenatal exposure to morphine alters analgesic responses and preference for sweet solutions in adult rats. Pharmacol Biochem Behav. 1996;55(4):629-34.

50. de Castro A, Jones HE, Johnson RE, Gray TR, Shakleya DM, Huestis MA Maternal methadone dose, placental methadone concentrations, and neonatal outcomes. Clin Chem. 2011;57(3):449-58. doi:10.1373/clinchem.2010.154864.
51. Tsai RY, Chou KY, Shen CH, Chien CC, Tsai WY, Huang YN, et al. Resveratrol regulates $\mathrm{N}$-methyl-D-aspartate receptor expression and suppresses neuroinflammation in morphine-tolerant rats. Anesth Analg. 2012;115(4):944-52. doi:10.1213/ANE.0b013e31825da0fb.

52. Sedaghati M, Vousooghi N, Goodarzi A, Yaghmaei P, Mokri A, Zarrindast MR. Expression of NR3B but not NR2D subunit of NMDA receptor in human blood lymphocytes can serve as a suitable peripheral marker for opioid addiction studies. Eur J Pharmacol. 2010;633(1-3):50-4. doi:10.1016/j.ejphar.2010.02.007.

53. Lee M, Silverman SM, Hansen H, Patel VB, Manchikanti L. A comprehensive review of opioid-induced hyperalgesia. Pain Physician. 2011;14(2):145-61.

54. Mutschler J, Koopmann A, Grosshans M, Hermann D, Mann K, Kiefer F. Dextromethorphan withdrawal and dependence syndrome. Dtsch Arztebl Int. 2010;107(30):537-40. doi:10.3238/arztebl.2010.0537.

55. Yang SN, Yang JM, Wu JN, Kao YH, Hsieh WY, Chao CC, et al. Prenatal exposure to morphine alters kinetic properties of NMDA receptor-mediated synaptic currents in the hippocampus of rat offspring. Hippocampus. 2000;10(6):654-62. doi:10.1002/1098-1063(2000)10:6<654::AID-HIPO1003>3.0.CO;2-T.

56. Li Z, Wu CF, Pei G, Xu NJ. Reversal of morphine-induced memory impairment in mice by withdrawal in Morris water maze: possible involvement of cholinergic system. Pharmacol Biochem Behav. 2001;68(3):507-13.

57. Slamberova R, Schindler CJ, Pometlova M, Urkuti C, Purow-Sokol JA, Vathy I. Prenatal morphine exposure differentially alters learning and memory in male and female rats. Physiol Behav. 2001;73(1-2):93-103.

58. Niu L, Cao B, Zhu H, Mei B, Wang M, Yang Y, et al. Impaired in vivo synaptic plasticity in dentate gyrus and spatial memory in juvenile rats induced by prenatal morphine exposure. Hippocampus. 2009;19(7):649-57. doi:10.1002/hipo.20540.

59. Barnes MJ, Holmes G, Primeaux SD, York DA, Bray GA. Increased expression of mu opioid receptors in animals susceptible to diet-induced obesity. Peptides. 2006;27(12):3292-8. doi:10.1016/j.peptides.2006.08.008.

60. Fu Y, Xie C, Yan M, Li Q, Joh JW, Lu C, et al. The lipopolysaccharide-triggered mesangial transcriptome: Evaluating the role of interferon regulatory factor-1. Kidney Int. 2005;67(4):1350-61. doi:10.1111/j.1523-1755.2005.00212.x.

\section{Submit your next manuscript to BioMed Central and take full advantage of:}

- Convenient online submission

- Thorough peer review

- No space constraints or color figure charges

- Immediate publication on acceptance

- Inclusion in PubMed, CAS, Scopus and Google Scholar

- Research which is freely available for redistribution 